\title{
Festival de Declamação: em prol da leitura e da oralidade nos ensinos básico e superior
}

Recitation Festival: for reading and orality in basic and higher education

\author{
Alexandra Santos Pinheiro* \\ Edilaine Buin ${ }^{* *}$
}

\author{
Digo: o real não está na saída nem na chegada: ele se dispõe \\ para a gente é no meio da travessia (ROSA, 2005, p. 80).
}

\section{Resumo}

Neste relato de experiência, refletimos sobre os cinco anos do projeto de extensão intitulado "Festival de Declamação". A ação, que nasceu, em 2013, como uma das principais atividades do Programa de Bolsa de Iniciação à Docência (Pibid), engloba autores diversificados: acadêmicos e professores do curso de Letras e estudantes e professores das escolas públicas da cidade de Dourados, no Mato Grosso do Sul. Mais do que relatar o projeto, refletimos sobre as dificuldades em mediar a leitura e a interpretação na educação básica e na universidade e demonstramos como a poesia/o poema contribui para essa tarefa, ao mesmo tempo em que torna visível sujeitos que se perdem em ambientes escolares marcados pela superlotação e pela precária estrutura. A comunidade envolvida na organização do projeto, que atingiu estudantes de seis escolas públicas de Dourados, MS, formada por acadêmicos que integram não somente o Pibid, de onde partiu a ação, mas também do Projeto de Ensino Tutorial (PET), e professores da rede pública, que atuam como supervisores e aceitam o desafio de fugir à rotina escolar, promovendo um espaço de formação importante, quase nunca possibilitado pelo excesso de conteúdo programático estipulado pelos órgãos governamentais.

Palavras-chave: Extensão. Leitura. Poesia.

\section{Abstract}

In this article, we reflect on the five-year extension project "Recitation Festival." The action, which was born in 2013 as an extension project, one of the principal activities of the Program of Incentive to Teaching (Pibid), includes diverse authors: academics and professors of the major in Letters and students and teachers of the public schools of Dourados city in Mato Grosso do Sul state. More than reporting the project, we reflect on the difficulties in mediating reading and interpretation in Basic Education and in the University level and demonstrate how Poetry contributes to this task while, at the same time, making it visible for those subjects that are lost in school environments marked by overcrowding and precarious structure. The community involved in the project organization, which currently reaches students from six public schools in Dourados, MS, made up of academics that integrate valuable programs such as the Pibid and the Tutorial Teaching Project (PET) and teachers who act as supervisors of the Pibid, are subjects that accept the challenge of escaping school routine, promoting an important training space, almost never made possible by the excess of program stipulated by the government agencies.

Keywords: Extension. Reading. Poetry.

Recebido em 15/02/2018 - Aprovado em 31/08/2018

http://dx.doi.org/10.5335/rep.v26i1.7880

Doutora em Teoria e História Literária pela Universidade Estadual de Campinas (Unicamp). Professora da Universidade Federal da Grande Dourados (UFGD). Suas pesquisas e publicações estão voltadas, principalmente, aos temas: literatura e gênero; história da leitura e ensino da literatura. E-mail: alexandrasantospinheiro@yahoo.com.br

** Doutora e mestre em Linguística pela Unicamp, nas áreas de Linguística Textual e de Aquisição da Escrita, respectivamente. Professora da UFGD. Acumula experiência nos ensinos superior e básico e também na formação continuada de professores. E-mail: edilainebuin@gmail.com 


\section{Palavras iniciais: situando o Declamando}

Em uma das reflexões mais lúcidas sobre poesia, Jorge Luis Borges afirma que: "A poesia, como veremos, está logo ali, à espreita" (2000, p. 11). As palavras do autor podem ser sentidas na prática quando assistimos a estudantes de escolas públicas de educação básica e de universidades subindo ao palco e declamando poemas que correspondem às expectativas de vida e às distintas maneiras de compreender o mundo. A criança, o jovem ou mesmo o adulto não precisa definir poesia para saber onde encontrá-la. Borges também não a definiu. Preferiu demonstrar o quanto o texto poético está emaranhado no ser humano, que, por sua vez, também "é poesia". Assim como o poeta argentino, o presente texto não trata de definições, mas das sensações provocadas por vozes de crianças e de jovens que participaram das cinco edições do Festival de Declamação, projeto de extensão que concluiu sua $5^{\text {a }}$ edição, promovido pelo Programa de Bolsas de Iniciação à Docência (Pibid) e, mais recentemente, pelo Programa de Educação Tutorial (PET), ambos do Curso de Letras da Universidade Federal da Grande Dourados (UFGD). As declamações comprovaram que o gênero poema não deve ser apenas lido solitariamente, mas partilhado. No caso do presente texto, analisamos os resultados da partilha realizada entre mais de 600 estudantes da cidade de Dourados.

Na UFGD, o Pibid foi iniciado, no âmbito das diversas áreas do conhecimento, no ano de 2009. Inicialmente, eram 152 iniciantes à docência (IDs), um coordenador institucional, seis coordenadores de área e dez supervisoras. Oito anos depois, os envolvidos foram: 331 IDs, um coordenador institucional e três gestores, 27 coordenadores de área e 54 supervisores. ${ }^{1} \mathrm{O}$ aumento foi significativo, mas, com ele, vieram muitos problemas: as incertezas em relação à sua manutenção, o atraso nos repasses de custeio, a dificuldade em integrar de maneira interdisciplinar todas as áreas. De outro modo, os anos amadureceram a relação entre universidade e escolas parceiras. Conquistamos uma compreensão, por parte da direção e da coordenação das escolas de educação básica, em relação aos objetivos do programa. Os graduandos já não eram vistos como estagiários, mas como IDs, futuros professores em formação, e os supervisores reconheciam o seu duplo papel: formador e formando. No caso do Pibid-Letras da UFGD, os bastidores também são marcados por tentativas, fracassos e amadurecimentos, por aprendizagens que ocorrem no desafio de integrar teoria e prática.

Em 2012, o esforço das coordenadoras, uma doutora em linguística e a outra, em teoria literária, culminou em uma proposta que ofereceu, aos trinta graduandos bolsistas (divididos para aturarem em seis escolas parceiras) e aos seis supervisores, a oportunidade de pensar o ensino da linguagem sem que uma área se sobressaísse à outra. Assim, desde 2013, no Pibid-Letras, instituímos algumas ações permanentes no subprojeto: formação continuada, viagem cultural, prepa- 
ração e aplicação de aulas nas escolas, desenvolvimento de projetos pedagógicos, estudos sistemáticos, elaboração de caderno de campo, iniciação científica, ${ }^{2}$ Projeto Festival Declamando. Em 2017, umas das coordenadoras passou a ser tutora do PET-Letras, e, assim, pudemos unir os dois programas, visto por nós como os mais significativos para os cursos de licenciatura. Várias ações, antes lideradas apenas pelo Pibid, passaram a ser reelaboradas e executadas em conjunto com o PET. ${ }^{3}$

Desde 2013, encerramos as atividades anuais e reunimos, no auditório da universidade, estudantes das escolas parceiras para uma noite de declamação de poesia. O que se assiste na universidade é o resultado do trabalho desenvolvido durante o decorrer do segundo semestre em cada uma das instituições. $O$ festival ocorre em dois momentos: com a seleção interna nas escolas parceiras e com a apresentação dos grupos finalistas das seis escolas no auditório da universidade. Ao promover o Festival de Declamação, o Pibid-Letras da UFGD procurou cumprir com o ensino integral da língua materna: a prática da escrita, da oralidade e da reflexão sobre o patrimônio cultural que oferece a literatura. Somado a estes objetivos principais, o festival oportunizaria a confraternização entre as comunidades escolar e acadêmica.

O festival, em sua $5^{\text {a }}$ edição, contou com a parceria de seis escolas públicas e mudou-se para o Teatro Municipal da cidade. Ainda assim, parte da plateia necessitou ficar em pé para acompanhar as apresentações, como pode ser visualizado na imagem da Figura 1.

Figura 1 - Foto do dia 31 de outubro de 2017, no Teatro Municipal de Dourados, MS

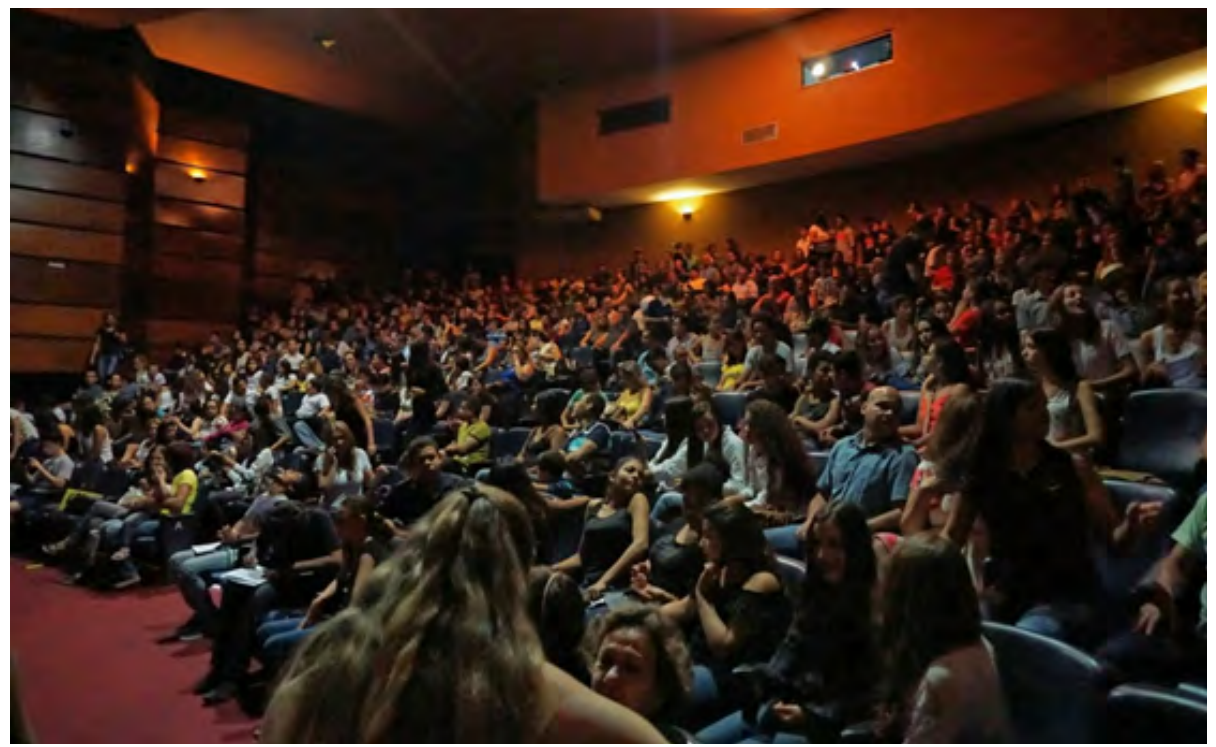

Fonte: arquivo das autoras. 
As regras para participar da seleção interna da escola eram: (1) formar grupos da mesma sala ou de salas diferentes com mais de oito pessoas; (2) memorizar o poema escolhido ou escrito por um membro do grupo; (3) ter a orientação de um professor (independente da área) para a preparação. Cada escola forma um corpo de jurado, define seus próprios critérios de avaliação e seleciona três grupos para representar a instituição. A atividade tomou uma dimensão não esperada e ultrapassou os objetivos iniciais. A poesia movimentou o olhar dos estudantes e dos professores que os ajudam a escolher o texto e a se prepararem para a seleção interna que ocorre em cada escola. Muito mais que evidenciar o produto (o Festival de Declamação), este texto pretende capturar aspectos relevantes do percurso para se chegar ao festival, o que envolve o desenvolvimento da leitura, da construção de sentidos e da prática da expressão oral de todos os envolvidos e, principalmente, dos alunos do ensino básico das seis escolas envolvidas.

Em todas as edições do Declamando, as escolas foram presenteadas com livros doados pela editora Ática e pelo recurso financeiro de pesquisa contemplada pelo edital Universal. ${ }^{4} \mathrm{O}$ prêmio, entregue aos diretores de cada escola, não tem sido 0 elemento responsável para que, a cada ano, o número de alunos declamadores aumente. Nesse processo, os desejos de ser visto, de ser ouvido, de declamar textos de própria autoria ou da autoria de terceiros são as justificativas mais relevantes. Para mostrar isso, a seguir, discorremos sobre as estruturas escolares em que o projeto se desenvolve; depois, focamos naquilo que o projeto mobiliza na aprendizagem.

\section{Driblando a falta de estrutura}

Ao refletir sobre a formação de leitores entre os jovens, Michèle Petit destaca a importância de se pensar a mediação entre os sujeitos com menor poder aquisitivo:

Em grande parte, é uma questão de meio social. Vimos como os interditos, os obstáculos, podem ser numerosos para os que provêm de um meio pobre, mesmo que tenham sido alfabetizados: poucos livros, a ideia de que a leitura não é para eles, a preferência que se dá às atividades compartilhadas em detrimento destes "prazeres egoístas", [...]. Acrescente-se a isso o fato de que, se for um rapaz, os amigos estigmatizam aquele que se dedica a essa atividade "afeminada", "burguesa", associada ao trabalho escolar (PETIT, 2008, p. 139).

Apesar das afirmações supracitadas estarem atreladas ao contexto francês, é possível aproximar a realidade analisada por Michèle Petit com a realidade das escolas públicas douradenses que participam dos festivais de declamação. Começamos pelo preço de livros no Brasil. De fato, em uma realidade marcada pela desigualdade social, o livro torna-se "artigo de luxo". Ocorre, entretanto, que ações como a do Plano Nacional Bibliotecas da Escola (PNBE), dentre outras, têm contribuído para a manutenção e a renovação dos acervos escolares no Brasil. A presença 
do livro no ambiente escolar compete com a falta de mediadores (profissionais da educação que valorizem a leitura literária e a não literária) e a falta de contato-vivência dos estudantes com o material impresso.

A função da literatura na educação básica, segundo Cosson (2006, p. 20), seria a de "sustentar a formação do leitor", mas, para que haja essa sustentação, o professor/mediador precisa ser um leitor. Muitos professores justificam a não prática da leitura devido à carga horária de trabalho e ao sistema que lhe é imposto, mas há que se dizer, contudo, que será um tanto mais difícil a existência de alunos leitores sem a figura de um professor leitor. Para esclarecer melhor esse ponto, Pinheiro nos traz uma reflexão muito importante em relação à formação de leitores, mencionando um exemplo de uma docente em contexto de formação continuada. Ela relata que, quando menor, uma professora tomou o livro dela e não devolveu mais:

[...] um tio lhe presenteou com um gibi. Foi o primeiro livro que ganhou. Ela ficou muito emocionada. Levou o gibi para a escola, queria mostrar para os colegas. Durante a aula, passou a ler as histórias em quadrinhos, distraiu-se e foi surpreendida pela professora que lhe tomou o gibi, fez um sermão e nunca mais lhe devolveu (PINHEIRO, 2011, p. 309).

Felizmente, a atitude dessa professora, ao limitar a formação dessa aluna, não teve um fim trágico, pois tal comportamento poderia ter prejudicado o futuro dela como leitora, mas a aluna conseguiu romper os obstáculos, tornando-se, mais tarde, uma professora, que soube dar outro valor à prática da leitura. Para que isso não ocorra na escola, é necessária a criação de projetos de leitura que conscientizem os professores do seu papel em relação ao ato de ler e que incentivem os alunos a ler literatura literária. Nesse sentido, Lajolo reitera que "[...] a organização de um projeto de leitura para a escola é fundamental" (2005, p. 13).

Pensamos que também nós, professoras universitárias, juntamente com graduandos em Letras, poderíamos focar a formação de leitores, nesse contexto desprivilegiado, como um de nossos principais objetivos. Além de chamar a atenção à falta de recursos, a declamação de poesias contribui para minimizar outro problema de estudantes e escolas carentes socioeconomicamente: a timidez de muitos grupos de posicionar-se em palco para declamar versos. Na realidade assistida por nós, também cabe "a ideia de que a leitura não é para eles". Ao declamar os poemas escolhidos, as crianças e os jovens dão os seus recados, falam de amor, de política, e registram que também para eles o cotidiano representa resistência e luta.

Nas seleções internas, todos os alunos da escola eram levados para a quadra de esporte, no intuito de aplaudirem os colegas que participariam da seleção. Em todas as escolas, o esforço da direção para que o festival interno aconteça é significativo, em relação à organização dos professores, dos funcionários, além de ter que driblar a falta de estrutura. Quanto a este último item, por exemplo, é preciso organizar os estudantes para retirarem as cadeiras da sala de aula a fim de terem onde sentar, e depois retornar todas, como evidenciam as imagens das Figuras 2 e 3. 
Figura 2 - Foto de setembro de 2017 - festival interno em escola parceira do Pibid-Letras

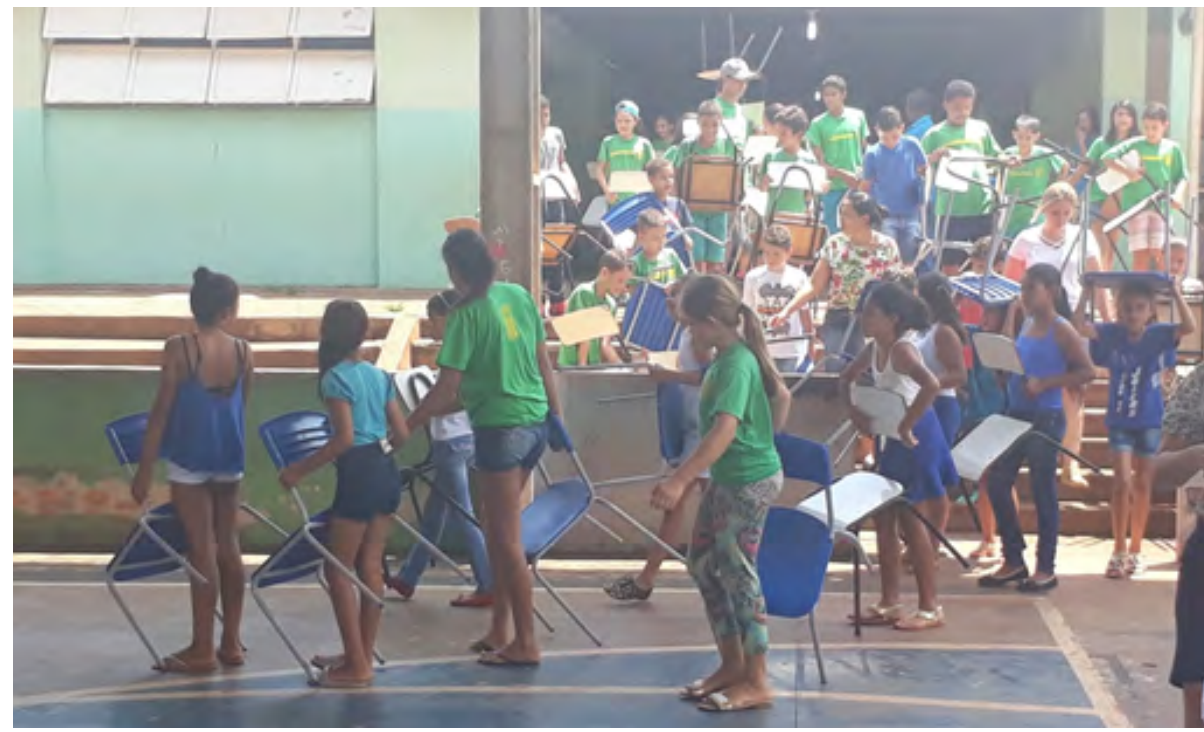

Fonte: arquivo das autoras.

* Entrada dos alunos na quadra, com suas cadeiras da sala de aula, para o Festival de Declamação.

Figura 3 - Foto de setembro de 2017 - festival interno em escola parceira do Pibid-Letras

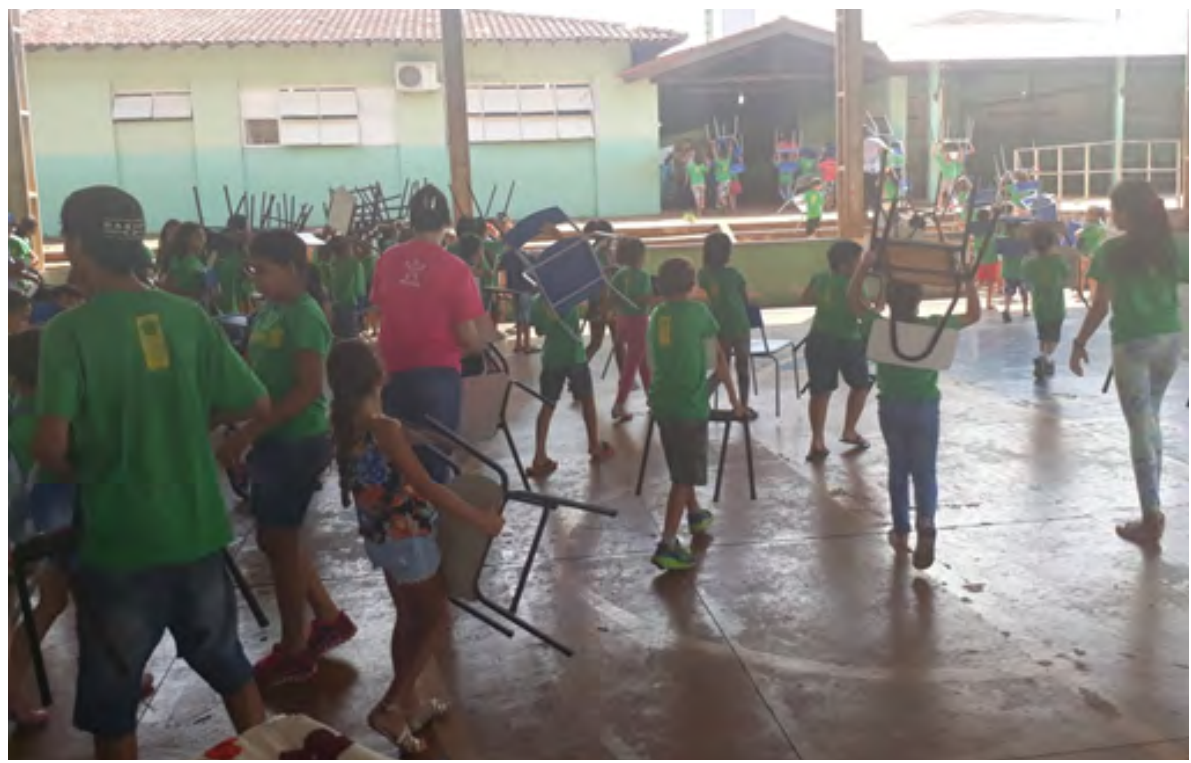

Fonte: arquivo das autoras.

* Saída dos alunos na quadra, com suas cadeiras, quando encerrado o Festival de Declamação. 
Não se pode deixar de observar que as quadras das escolas são cobertas por telhas de zinco, o que deixa as manhãs ou as tardes douradenses ainda mais quentes. Em algumas, lixos acumulados ao redor do espaço pareciam insistir que a ação "não era para eles". Mas foi. O silêncio, na maioria das vezes, instaurava-se no momento em que os grupos declamavam. A cada apresentação, aplausos e encantamentos. Assim como Petit, acreditamos que ações pedagógicas e políticas podem minimizar a distância entre crianças e jovens de poder aquisitivo menos favorecido e suprir, em parte, os materiais de leitura. Para que o resultado seja satisfatório, é preciso um trabalho insistente e contínuo, assumido por um grupo de profissionais que efetivamente promova a mediação de leitura e a formação de leitores.

Os gestores das escolas têm se surpreendido tanto com a participação ativa de seus estudantes, chamando a atenção para o fato de que crianças e adolescentes, em geral meninos considerados indisciplinados, que causam atritos e perturbam as aulas, têm se destacado na declamação pela capacidade de memorização e de desenvoltura na expressão oral. Nesse reconhecimento de professores e gestores que fazem a diferença em meio à falta de estrutura, citamos uma das escolas que é parceira do Pibid-Letras há quatro anos. Localizada na região central de Dourados, mas sem espaço para promover a seleção interna, a escola locou um auditório para o festival, a fim de melhorar a acústica e o conforto para os estudantes. É importante destacar, também, o empenho da instituição para que as famílias estivessem presentes na apresentação de seus filhos. Das seis escolas que participaram da última edição do projeto, apenas esta e mais uma da prefeitura, por estrutura própria, contaram com um espaço mais apropriado. As outras quatro ainda se mantiveram no calor das quadras e com a falta de acústica.

Sem espaço apropriado, parece ficar evidente o movimento de resistência. ${ }^{5} \mathrm{~A}$ estrutura da maioria das escolas desfavorece a atuação de estudantes protagonistas e inviabiliza a realização de ações que fujam da rotina da sala de aula. Resistir implica reagir contra a realidade escolar imposta às escolas públicas brasileiras. O Festival de Declamação promove a resistência por meio da arte, da poesia, e, no movimento de selecionar os textos, interpretá-los, ensaiar a apresentação, retirar a sua cadeira da sala de aula para prestigiar a apresentação dos colegas de outras salas e turmas, construímos a plateia da partilha.

\section{Em prol da leitura e da oralidade}

Por leitura, compreendemos não só o que está escrito. Ensinar a ler implica contribuir para que o cidadão desvende palavras, imagens, sons e, inclusive, o não dito. A partir deste raciocínio, Manguel (1997) defende que a história está repleta 
de leitores: existiram e existem leitores em todas as épocas, desde a antiguidade clássica até os dias atuais. Além disso, o autor chama a atenção para as leituras diversas ao afirmar que:

Ler as letras de uma página é apenas um de seus muitos disfarces. $\mathrm{O}$ astrônomo lendo um mapa de estrelas que não existem mais; o arquiteto japonês lendo a terra sobre qual será erguida uma casa, de modo a protegê-la das forças malignas; o zoológico lendo os rastros de animais na floresta; o jogador lendo os gestos do parceiro antes de jogar a carta vencedora; a dançarina lendo as notações do coreógrafo e o público lendo os movimentos da dançarina no palco; o tecelão lendo o desenho intrincado de um tapete sendo tecido; [...] - todos eles compartilham com os leitores de livros a arte de decifrar e traduzir signos (1997, p. 19).

Em espaços educacionais em que tantos os materiais didáticos quanto as estratégias dos docentes supervalorizam o artefato linguístico em detrimento da própria expressão e dos discursos, da função sociopragmática (BUIN, 2015), o Projeto Declamando inverte a ordem: prioriza o acontecimento, ou seja, a declamação e a sua partilha. Estudar conteúdos - tais como as figuras de linguagem, mudanças sintáticas das frases, os recursos linguísticos que propiciam sonoridade aos versos, a semântica construída nos versos - passa a ser necessário em função da interpretação no momento da declamação. É o evento, a prática social de declamação, que dá o eixo para os conteúdos que são ensinados durante o período em que se prepara para o festival interno das escolas. No decorrer do processo, portanto, muitos conteúdos de Língua Portuguesa são apresentados por meio da análise linguística, em função do que traz o poema e do que é essencial para a interpretação. Há, por vezes, trabalho de intertextualidade e com outros gêneros diferentes do poema, que são levados à sala de aula para ampliar o repertório dos estudantes e estabelecer relações com aquele que será declamado, tomado como principal naquela situação.

Imbuídos de significados, no processo de seleção e ensaio para o festival, os estudantes podem desfrutar da leitura em voz alta, uma ação tão presente no século XIX e no início do século XX no Brasil, mas que perdeu, por diferentes motivos, o seu espaço entre as metodologias levadas para a sala de aula. Sobre o assunto, citamos a seguir dois posicionamentos importantes:

A leitura em voz alta, feita pelos adultos, é lembrada continuamente, pela maioria das pessoas, como uma de suas primeiras associações agradáveis com a leitura. Ler para os alunos é um dos métodos mais efetivos para criar leitores capazes, os quais continuam optando por ler durante a vida (MORAIS, 2012, p. 52).

[...] a leitura em voz alta pressupõe a partilha de palavras, figuras, ideias, pontos de vista, rimas e ritmos; por meio dela compartilhamos a dor e o consolo, a esperança e o medo das grandes questões que são parte de nossa vida (RIGOLETO; DI GIORGI, 2009, p. 233). 
Tanto Morais (2012) quanto Rigoleto e Di Giorgi (2009) chamam a atenção para o aspecto afetivo do processo de formar leitores. Partilhamos, em voz alta, palavras, ideias e sentimentos. Durante os ensaios nas escolas, era nítido que a leitura em voz alta também possibilitava o processo coletivo de interpretação, uma vez que versos e estrofes eram repetidos com diferentes entonações, a depender do entendimento do estudante. Também era nítido o amadurecimento dos grupos, que iniciavam os ensaios de maneira tímida, duvidando daquilo que executavam, e terminavam cúmplices, seguros de que haviam chegado à melhor interpretação para o texto literário escolhido.

Dessa forma, a leitura de diversos poemas e de suas interpretações acontece em função de um momento significativo, por isso ganha sentido. Mas não é fácil, na maioria das vezes, convencer coordenadores e professores disso. Era comum argumentarem que, com o festival, estariam perdendo tempo, que era preciso passar o conteúdo e não ficar declamando poesia, que era necessário preparar alunos para o desempenho nas avaliações governamentais e para passarem no vestibular. No entanto, é evidente que o decorrer dos anos sem o exercício da declamação não garantiu tal sucesso nos exames. Assim, insistimos com os educadores que, primeiramente, é preciso sentir, para, posteriormente, pensar de modo mais racional, focando nas estruturas, nos elementos coesivos, que possibilitam as sensações.

O festival traz a necessidade da leitura e da expressão corporal. É em função de ser protagonista da ação que a prática de declamação é priorizada, deixando os recursos da linguagem, que no geral ganham prioridade na força da tradição gramatical, em segundo plano, como suporte para interpretação e não como o fim em si. Ganha-se, no enfrentamento do público, em desenvoltura, em leitura. Abre-se um feixe de luz, um espaço para a voz daqueles que são de fato a demanda principal e que, geralmente, são "apagados", em função de demandas burocráticas impostas para aumentar índices numéricos, como o Índice de Desenvolvimento da Educação Básica (Ideb), ${ }^{6}$ por exemplo.

Concordamos com Nunes (1996), assim como Neves (2016), que a leitura de poema (e incluímos tanto a leitura silenciosa quanto a prática da oralidade, para a partilha) é um exercício indispensável à humanização, pelo exercício ético e estético que propicia. A experiência de leitura, de que fala o autor, transita para a experiência comum do leitor. Neves explica que:

[...] o leitor volta a si compreendendo o texto. Compreendendo o texto compreende a si e vice-versa. Compreender é compreender-se diante do texto. Trata-se de uma revelação de nós mesmos e do outro, fundamental para a ética da leitura. Essa revelação é confiada ao leitor, na medida em que o texto estimula sua imaginação e ativa sua reflexão $(2016$, p. 5). 
Alguns poemas de autoria dos próprios alunos e escolhidos para declamação são mais emotivos e/ou reflexivos, como os que homenagearam o estado do Mato Grosso do Sul, na ocasião em que completava 40 anos. Além dos textos poéticos produzidos pelos alunos, foram declamados, também, poemas de autores regionais e nacionais, a exemplo de Cecília Meireles, Cora Coralina, Manoel Bandeira, Manoel de Barros e Emanuel Marinho. Outros são de crítica social, como o poema Olga, de Andrade Serafim. Os textos escolhidos apontam para a forma com que crianças e jovens compreendem a realidade à sua volta; pela poesia, demarcam as suas identidades. O teórico Stuart Hall (2006) defende a ideia de que as identidades modernas estão sendo descentradas. Contudo, essas concepções se transformam, e o que, antes, era definido como fixo e estável está se tornando fragmentado, composto de várias identificações contraditórias. A identidade deixa de ser fixa para se tornar móvel e transformada continuamente em relação às representações culturais da sociedade em que vivemos. Dessa forma, seria definida historicamente e não biologicamente:

Dentro de nós há identidades contraditórias, empurrando em diferentes direções, de tal modo que nossas identificações estão sendo continuamente deslocadas. Se sentimos que temos uma identidade unificada desde o nascimento até a morte é apenas porque construímos uma cômoda estória sobre nós mesmos ou uma confortadora "narrativa do eu". A identidade plenamente unificada, completa, segura e coerente é uma fantasia. Ao invés disso, à medida em que os sistemas de significação e representação cultural se multiplicam, somos confrontados por uma multiplicidade desconcertante e cambiante de identidades possíveis, com cada uma das quais poderíamos nos identificar - ao menos temporariamente (HALL, 2006, p. 13).

De acordo com Stuart Hall (2006), não é possível compreender a identidade humana por completa, mas, provavelmente, por partes. Zygmunt Bauman (2005) discute preceitos semelhantes aos de Hall no que diz respeito às identidades multifacetadas: "Em nossa época líquido-moderna, o mundo em nossa volta está repartido em fragmentos mal coordenados, enquanto as nossas existências individuais são fatiadas numa sucessão de episódios fragilmente conectados" (2005, p. 18).

A época líquido-moderna destacada por Bauman (2005) pode ser relacionada à globalização, que faz com que as relações interpessoais ocorram de modo mais fácil e, consequentemente, rápido. Vivemos em um mundo de transformação, em que as coisas surgem e desaparecem com muita rapidez. Essa sociedade, muitas vezes instável, transfere insegurança às pessoas, causando uma sensação de deslocamento constante. Afinal, nossas identidades vão sendo construídas e transformadas justamente nessa relação entre o "eu" e o "outro". Neste ponto, precisamos destacar uma experiência em especial, porque acreditamos que ela sintetiza, em parte, o embate que, ao longo das edições do Declamando, vivenciamos nas escolas 
parceiras do Pibid. Um jogo contínuo de convencimento para garantir um ensino de língua materna coerente com a realidade e os anseios dos estudantes.

Embora fosse solicitado aos participantes do Pibid e do PET-Letras que divulgassem as regras do Declamando nas salas de aula e fizessem também a inscrição dos grupos, alguns professores tomavam para si esta tarefa, selecionando, algumas vezes, apenas as salas consideradas "mais comportadas". Certa vez, fomos acompanhar as oficinas ministradas pelos IDs e perguntamos a um grupo do terceiro ano do ensino médio por que eles não se inscreveram para o festival. Soubemos, então, que a professora de Língua Portuguesa havia explicado que ela já havia decidido quem participaria. Conversamos com a professora e nos comprometemos a acompanhar a turma para evitar transtornos, uma vez que ela refutava o nosso pedido porque defendia que turmas que causavam tumulto não mereciam participar.

Vencido este primeiro embate, fomos surpreendidas por um segundo. O grupo escolheu a letra de Mulamba, do grupo Mulamba, para declamar e cantar. Chegamos para o ensaio e descobrimos que a professora havia alterado alguns trechos da letra porque os considerou "ofensivos". A título de ilustração, segue um trecho original que foi submetido à alteração:

Eu sou aquilo que ninguém mais acredita

Eu sou a puta, eu sou a santa e a banida

Sou a bravura e os surtos de Anita Garibaldi

Bandeira baixa ou bandeira que agita

O termo "puta" havia sido trocado por "meretriz". Então, explicamos para a professora que a palavra aparecia dentro de um contexto de protesto e que por isso não ofenderia ninguém. Certa de que a turma não seria selecionada, ela aceitou manter a versão original. Para surpresa de toda a escola, aquele grupo, considerado "um problema", foi o único a fazer uma apresentação com coreografia, violão e faixas de protesto contra a violência de gênero. Com muita animação, o grupo conquistou o primeiro lugar na seleção da escola e, certamente, pela força da expressividade e da criticidade, teria sido um dos finalistas se o momento final do Declamando tivesse esse objetivo. A própria professora de português, que vetou, inicialmente, a participação da classe, expressou a sua surpresa diante do que assistiu. Longe de reconhecer o mérito da turma, ela atribuiu o sucesso ao fato de que o grupo foi acompanhado por nós da universidade. Isso, entretanto, não faz sentido, pois apenas orientamos, como aconteceu com todos os outros grupos de todas as escolas participantes. A coreografia e as faixas, por exemplo, foram resultados das ideias surgidas na turma e da autonomia que foi dada para decidirem sobre a própria apresentação. 
Essa experiência, assim como tantas outras que poderiam ser destacadas, comprova o fato de que o poema traz a lógica dos acontecimentos históricos e sociais marcantes para os estudantes, que, na ação crítica e na experiência da literatura, poderão construir uma nova história, de forma mais humana e justa. No âmbito do ensino de língua materna, os alunos poderão fazer emergir/transparecer uma face de sua identidade, por vezes, escondida ou opaca. Propiciar tal experiência dá uma dimensão muito maior à atividade de leitura estética, que atinge um alvo que está muito além do próprio desenvolvimento da leitura e da expressão oral: o de formar cidadãos críticos, que tenham mobilizados, por intermédio de vivências escolares significativas, recursos que lhes permitam atuar como pessoas éticas, como cidadãos críticos e atuantes.

\section{Uma possível conclusão}

O Festival Declamando por si só, embora seja o que inspira este texto, não é o foco principal da reflexão proposta neste relato. Como é possível observar, retomando João Guimarães Rosa, o que mais importa é a travessia: “[...] o real não está na saída nem na chegada: ele se dispõe para a gente é no meio da travessia" (2005, p. 80). Travessia marcada por escolhas, leituras, espaços desconfortáveis, aprimoramento dos espaços, pelo chamado à declamação de alunos pobres, cujo objetivo maior de estarem na escola, muitas vezes, é o próprio alimento (no sentido literal). Ao longo da análise, destacamos a resistência por parte da instituição escolar, que reage a um sistema que exige índice de aprendizagem incompatível com a estrutura ofertada. Mas, antes de concluir, é preciso destacar a resistência dos acadêmicos que integram programas valiosos como o Pibid e o PET e dos professores da rede pública que atuam como supervisores do Pibid. São sujeitos que aceitam o desafio de fugir à rotina escolar, que integram vida à sua prática e que promovem espaços de formação, que nem sempre são possibilitados pelo excesso de conteúdo programático estipulado pelos órgãos governamentais.

O projeto Festival Declamando oportunizou que a poesia efetivamente entrasse em sala de aula. Para lotarmos o Teatro Municipal (com capacidade para 600 pessoas), necessitamos trilhar o caminho do convencimento. Ao longo dos cinco anos de atuação, as coordenadoras de área visitaram as escolas parceiras, convencendo gestores e professores de sua importância. O que sempre precisou de convencimento deveria ser parte da rotina escolar, mas, infelizmente, na realidade atual, a escola vem sendo atropelada com questões burocráticas, que a desfocam do seu sentido principal: promover o desenvolvimento intelectual e social dos estudantes. 
O Pibid, devido a ações governamentais mais recentes, apesar da luta para que o projeto continuasse tal como foi idealizado, mudou de rumo. Nós, autoras, não atuamos mais como coordenadoras nem voluntárias; o caminho foi trilhado e seguirá com outros passos. Nosso maior desejo (ou sonho) é que as sementes plantadas pelo projeto de extensão, idealizado e executado nesses cinco anos no âmbito do Pibid, possam render frutos: que as escolas públicas parceiras possam manter seus festivais internos e que os acadêmicos possam levar a poesia para outros ambientes, para outras escolas. Ao longo dos cinco anos de travessia do Festival de Declamação, tornamos realidade aquilo que parecia utopia: o texto poético deu visibilidade aos estudantes das escolas públicas de Dourados parceiras do projeto. Permitiu a partilha dos sentimentos, dos protestos e do riso. Mas, também há pedras no decorrer da travessia. Para que o VI Declamando aconteça, ou não, depende-se não só dos novos participantes, mas também dos equívocos ou dos acertos provenientes dos órgãos governamentais.

\section{Notas}

1 Conforme informação cedida pela coordenadora institucional do Pibid da UFGD, Noemia Moura.

2 Incentivamos os participantes do Pibid a serem pesquisadores. Os trinta bolsistas são motivados a desenvolverem, como voluntários, uma pesquisa de iniciação científica. Desse esforço, já comemoramos cinco aprovações em programas de mestrado e uma aprovação em nível de doutorado.

3 Alexandra Santos Pinheiro foi coordenadora até 2016, deixando o cargo para assumir a tutoria do PET. Eliane Aparecida Miqueletti assumiu a coordenação desde então, em parceria com Edilaine Buin.

4 Agradecemos o financiamento do Conselho Nacional de Desenvolvimento Científico e Tecnológico (CNPq) concedido à pesquisa "Entre vidas e leituras: análise das práticas de leitura literária dos formandos do curso de Letras da UFGD-MS”, da professora Alexandra Santos Pinheiro. Foi com este recurso que, nos últimos dois festivais, conseguimos presentear as bibliotecas das escolas parceiras com obras literárias de Ligia Bojunga.

5 O conceito de resistir empregado neste artigo dialoga com o pensamento da filósofa Marilena Chauí. Para aprofundamento, indicamos os textos dela: O nacional e o popular na cultura brasileira (1983) e Considerações sobre o realismo político (1984).

${ }^{6}$ O Ideb foi criado em 2007, desde então, os seus resultados têm sido tomados como parâmetro para as propostas de políticas públicas educacionais. O resultado de 2016 na cidade de Dourados está disponível em: $<$ http://ideb.inep.gov.br/resultado/>. Acesso em: 6 jun. 2018. 


\section{Referências}

BAUMAN, Zygmunt. Identidade. Rio de Janeiro: Jorge Zahar, 2005.

BORGES, Jorge Luis. Esse ofício do verso. Trad. José Marcos Macedo. São Paulo: Companhia das Letras, 2000.

BUIN, Edilaine. Coerência textual na escola e práticas de letramento. Raído, Dourados, MS, v. 18 , p. $85-115$, jan./jun. 2015.

CHAUÍ, Marilena. Considerações sobre o realismo político. In: Desvios. São Paulo: Paz e Terra, 1984. v. 3. p. 7-28.

CHAUÍ, Marilena. O nacional e o popular na cultura brasileira. São Paulo: Brasiliense, 1983.

COSSON, Rildo. Letramento literário: teoria e prática. São Paulo: Contexto, 2006.

HALL, Stuart. A identidade cultural na pós-modernidade. Rio de Janeiro: DP\&A, 2006.

LAJOLO, Marisa. Meus alunos não gostam de ler... O que eu faço? Campinas: Unicamp/Cefiel/ MEC, 2005.

NEVES, Cynthia Agra de Brito. Leitura em sala de aula: um exercício indispensável à humanização. In: REUNIÃO ANUAL DA ASSOCIAÇÃO NACIONAL DE PÓS-GRADUAÇÃO E PESQUISA EM EDUCAÇÃO, 32, 2009, Caxambu. Anais... Timbaúba: Espaço Livre, 2016. v. 1. p. 1-16.

NUNES, Benedito. Ética e Leitura. Leitura: Teoria e Prática, Porto Alegre: ABL/Mercado Aberto, ano 15, n. 27, p. 01-12, jun. 1996.

MANGUEL, Alberto. Uma história da leitura. Trad. Pedro Maia Soares. São Paulo: Companhia das Letras, 1997.

MORAIS, Elaine M. Formam-se leitores nas bibliotecas escolares? In: PAIVA, A. (Org.). Literatura fora da caixa: o PNBE na escola - distribuição, circulação e leitura. São Paulo: Editora Unesp, 2012. p. 39-71.

PETIT, Michèle. Os jovens e a leitura: uma nova perspectiva. Trad. Celina Olga de Souza. São Paulo: Editora 34, 2008.

PINHEIRO, Alexandra Santos. Letramento literário: da escola para o social e do social para escola. In: GONÇALVES, Adair Vieira; PINHEIRO, Alexandra Santos (Org.). Nas trilhas do letramento: entre teoria, prática e formação docente. Campinas, SP: Mercado das Letras; Dourados, MS: Editora da Universidade Federal da Grande Dourados, 2011. p. 131-145.

RIGOLETO, Ana Paula Cardoso; DI GIORGI, Cristiano. Outros parceiros na biblioteca escolar: democratização e incentivo à leitura. In: SOUZA, R. J. (Org.). Biblioteca escolar e práticas educativas. Campinas: Mercado de Letras, 2009. p. 219-237.

ROSA, João G. Grande sertão: veredas. São Paulo: Nova Fronteira, 2005. 